\title{
Radicular Peroxide Penetration from Different Concentrations of Carbamide Peroxide Gel during Intracoronal Bleaching-An In vitro Study
}

\author{
Karayil Binu Nathan ${ }^{1}$, Roopa R Nadig ${ }^{2}$, Tisson Varghese Job ${ }^{3}$, Puthan Veetil Nithin ${ }^{4}$, Rajesh Karthik ${ }^{5}$, Sailaja Choudary ${ }^{6}$
}

\begin{abstract}
Aim: The aim of this study is to evaluate and compare the amount of radicular peroxide penetration when various concentrations of carbamide peroxide (CP) bleaching gels (10, 15, and $35 \%$ ) and a mixture of $30 \%$ hydrogen peroxide (HP) with sodium perborate are used for intracoronal bleaching.

Materials and methods: Fifty extracted single-rooted premolars from young adults were used. The specimens were then divided into five groups such that teeth with varying sizes were equally distributed in all groups. Group I-distilled water (control group), group II-10\% CP, group III-15\% CP, group IV-35\% CP, and group V-30\% HP with sodium perborate. Intermediate restorative material (IRM) was used to seal access cavities and left for a week at $37^{\circ} \mathrm{C}$ in an incubator. Following the bleaching process, suspended teeth from plastic tubes containing distilled water were removed and the water was used to determine the amount of peroxide levels. A UV-visible spectrophotometer at a wavelength of $480 \mathrm{~nm}$ was used to determine the quantity of peroxide based on the optical density.

Results: Results showed the highest peroxide leakage in group V, followed by group IV, and then group III, whereas the least peroxide penetration was found in group II, and the control group or group I showed no penetration. The Kruskal-Wallis test showed a significant difference between the various groups tested. The Mann-Whitney test was done to find in which pair of groups there exists a significant difference. It was found that all the groups when compared among themselves showed a significant difference.

Conclusion: The present study concluded that lower concentrations of CP 10 and 15\% produced lower peroxide leakage. Hence, it could be tried as an alternate to traditional agents in cases with compromised tooth which shows cervical tooth defects where the risk of external root resorption is higher.

Clinical significance: The management of discolored teeth involves different techniques; among various techniques, bleaching is considered to be a safe, effective, and relatively noninvasive technique to lighten discolored teeth and it also conserves dental hard tissue.

Keywords: Bleaching, Carbamide peroxide, Discolored teeth, Hydrogen peroxide.

The Journal of Contemporary Dental Practice (2019): 10.5005/jp-journals-10024-2563
\end{abstract}

\section{INTRODUCTION}

Discoloration of anterior teeth especially those which are root canal treated results in considerable cosmetic impairment. Discoloration of root canal-treated teeth may occur because of the incorporation of breakdown products from pulpal hemorrhage, incompletely removed pulpal remnants, or from root canal filling materials and sealers containing eugenol or silver salts that get released from postendodontic amalgam restoration. ${ }^{1}$ One of the most important factors in the management of aesthetics is the correction of tooth discoloration, because discoloration is more rapidly perceived than other aesthetic abnormalities.

The management of discolored teeth involves different techniques and approaches, such as microabrasion, macroabrasion, bleaching, and invasive therapies like crowns or placement of veneers made from porcelain or composite resin. Among these various techniques, bleaching is considered to be a safe, effective, and relatively noninvasive technique to lighten discolored teeth and it also conserves dental hard tissue. Nonvital tooth bleaching has shown to have a high success rate. ${ }^{2}$ Intracoronal bleaching is done as a thermocatalytic technique, as a walking bleach technique, or a combination of both. Hydrogen peroxide (HP) is commonly used in the concentration of 30 to $35 \%$, either alone or in combination with sodium perborate.

The thermocatalytic technique uses 30-35\% HP placed in the pulp chamber and is activated by heat. However, there are serious
$1,3,4,5$ Department of Conservative Dentistry and Endodontics, Educare Institute of Dental Sciences, Malappuram, Kerala, India

${ }^{2}$ Department of Conservative Dentistry and Endodontics, Dayananda Sagar College of Dental Sciences, Bengaluru, Karnataka, India

${ }^{6}$ Department of Oral Medicine and Radiology, Vokkaligara Sangha Dental College \& Hospital, Bengaluru, Karnataka, India

Corresponding Author: Karayil Binu Nathan, Department of Conservative Dentistry and Endodontics, Educare Institute of Dental Sciences, Malappuram, Kerala, India, Phone:+91 9895980043,e-mail:drbinunathan@ gmail.com

How to cite this article: Nathan KB, Nadig RR, et al. Radicular Peroxide Penetration from Different Concentrations of Carbamide Peroxide Gel during Intracoronal Bleaching-An In vitro Study. J Contemp Dent Pract 2019;20(5):587-592.

\section{Source of support: Nil}

Conflict of interest: None

complications of external root resorption reported which are associated with intracoronal bleaching. The reported incidence of external root resorption ranged from 0 to $6.9 \% .^{3}$

There has been a search for alterative bleaching agents that are as effective as the traditional ones but without the associated complications. The use of carbamide peroxide (CP) gel represents an alternative for nonvital tooth bleaching. CP breaks down into water, 
$\mathrm{HP}$, and urea, the HP concentration being approximately one-third of the original CP concentration used. This product finally releases nascent oxygen and water. This nascent oxygen will bleach the tooth. Acceptable aesthetic outcomes have been found in a walking bleach technique using 37\% CP gel. Studies have shown that both $35 \% \mathrm{CP}$ and $35 \% \mathrm{HP}$ when used for intracoronal bleaching were equally effective and significantly better than sodium perborate after 7 days. It has been reported that intracoronal bleaching with $35 \%$ CP gel produced a low level of HP diffusion into the periradicular region, comparable with sodium perborate and significantly lesser than the use of $30 \% \mathrm{HP}^{4}$

Although a lower concentration of CP eventually achieves the same result as the higher concentration, a longer time is needed to whiten the teeth using CP. ${ }^{5}$ However, there is less information available about the amount of cervical peroxide penetration, when different concentrations of $\mathrm{CP}$ gels are used. It is, therefore, clinically desirable to find out if a lower concentration of $\mathrm{CP}$ reduces the cervical peroxide penetration which would correlate to reduce the incidence of cervical resorption especially in the case of compromised tooth.

\section{Materials and Methods}

The present in vitro study was conducted in the Department of Conservative Dentistry and Endodontics, Dayananda Sagar College of Dental Sciences, Bengaluru, India.

A total of 50 single-rooted premolars were selected which were extracted for orthodontic reasons (Fig. 1) and were cleaned of calculus; a gauze soaked in $2.5 \%$ sodium hypochlorite was used to remove the soft tissue covering the root surface and stored in distilled water.

The extracted teeth were examined under a microscope with a magnification of $10 \times$ for cracks and other defects. Teeth exhibiting such defects were discarded. Endodontic access cavities were prepared on the occlusal surface and the root canal preparation was done using a step-back technique. Apical foramen was enlarged to size 35 (ISO size) (Fig. 2). The lateral compaction technique was followed to fill root canal using gutta-percha and $\mathrm{AH}$ plus sealer. Using Gates Gliden drills and hot plugger, the gutta-percha filling was removed $4 \mathrm{~mm}$ below the cementoenamel junction (CEJ).

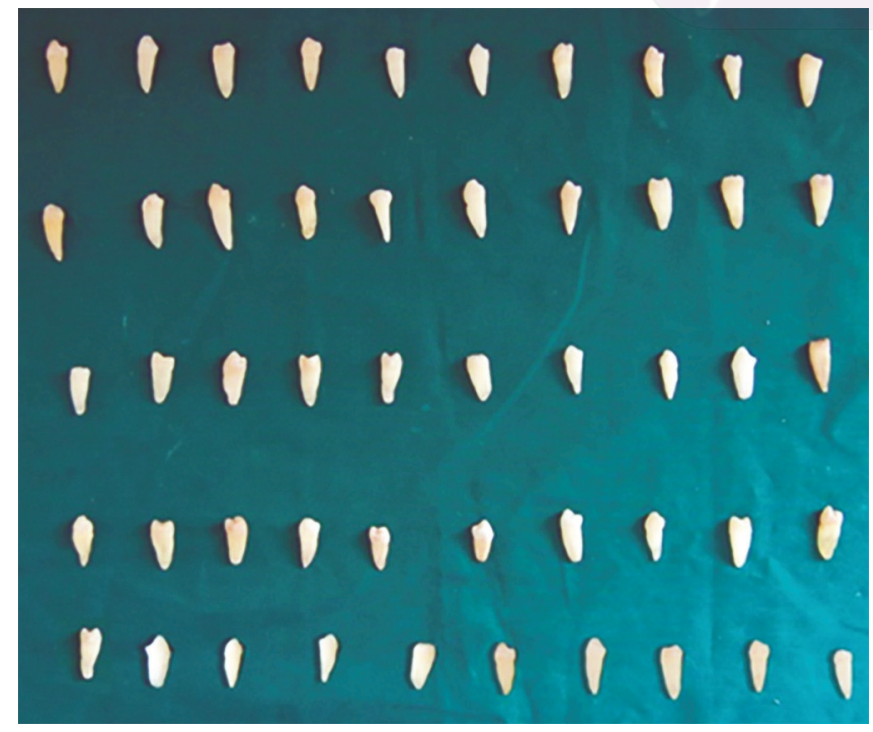

Fig. 1: Extracted human premolars
Remnants of gutta-percha and sealer were removed from the access cavity with a cotton pellet soaked in alcohol and distilled water was used thoroughly to rinse the pulp chamber of all teeth.

A $2 \mathrm{~mm}$ thick layer of glass ionomer cement (Universal restorative $\mathrm{GIC}$ ) as a base was applied. The outer root surface including the apical foramina was sealed with wax and coated with two layers of nail polish except the cervical third of the root. Teeth were mounted with parafilms and placed in plastic tubes containing $5 \mathrm{~mL}$ of distilled water such that the entire root, including the CEJ, was immersed. Specimens were placed in an incubator at $37^{\circ} \mathrm{C}$ for 1 hour.

\section{Group Distribution}

The specimens were then distributed into five groups such that teeth with varying sizes were equally distributed in all groups (Table 1 and Fig. 3).

Group I: control group, the pulp chamber was filled with cotton pellet soaked in distilled water.

Group II: the pulp chamber was filled with $10 \%$ CP gel (Opalascence PF, Ultradent Products Inc.).

Group III: the pulp chamber was filled with $15 \%$ CP gel (Opalascence PF, Ultradent Products Inc.).

Group IV: the pulp chamber was filled with $35 \%$ CP gel (Opalascence PF, Ultradent Products Inc.).

Group V: the pulp chamber was filled with a paste consisting of $2 \mathrm{~g}$ of sodium perborate (Merck Specialities Private Limited) mixed with 30\% HP (Merck Specialities Private Limited).

Temporary filling materials (IRM) were used to completely seal the access cavities and were kept in an incubator for 7 days at $37^{\circ} \mathrm{C}$ at $100 \%$ humidity to enact the oral environment.

\section{Procedure for Radicular Peroxide Penetration Assessment}

Following the bleaching treatment, teeth were removed from the plastic tubes. Using the ferrothiocyanate method, the amount of peroxide in each tube was measured (Fig. 4). Peroxide oxidizes colorless ferrothiocyanate to red ferrothiocyanate, and the optical density of was measured using a UV-Visible spectrophotometer at a wavelength of $480 \mathrm{~nm}$ (at room temperature).

\section{Preparation of Dye}

As ferrothiocyanate dye was known to be unstable, it was freshly prepared. About $1.92 \mathrm{~g}$ of ammonium ferrous sulfate was mixed in $500 \mathrm{~mL}$ of distilled water to get a concentration of 10 millimolar concentration of ammonium ferrous sulfate solution and $24.2 \mathrm{~g}$ of potassium thiocyanate was mixed in $100 \mathrm{~mL}$ of distilled water to get a $2.5 \mathrm{M}$ concentration of potassium thiocyanate solution. For each $2 \mathrm{~mL}$ of the peroxide containing solution taken from the tube containing tooth specimens, $540 \mathrm{~mL}$ of ammonium ferrous sulfate and $270 \mathrm{~mL}$ of potassium thiocyanate were added (Figs 5A and B). The optical density of the color change was recorded by using a UV-visible spectrophotometer (Fig. 6).

A standard calibration curve was obtained by using 30\% stock solution which was diluted with distilled water. The amount of HP in samples was then determined by comparing it to the standard calibration curve.

\section{Statistical Analysis}

The values, thus, obtained were statistically analyzed using the Kruskal-Wallis analysis of variance and the Mann-Whitney $U$ test. 


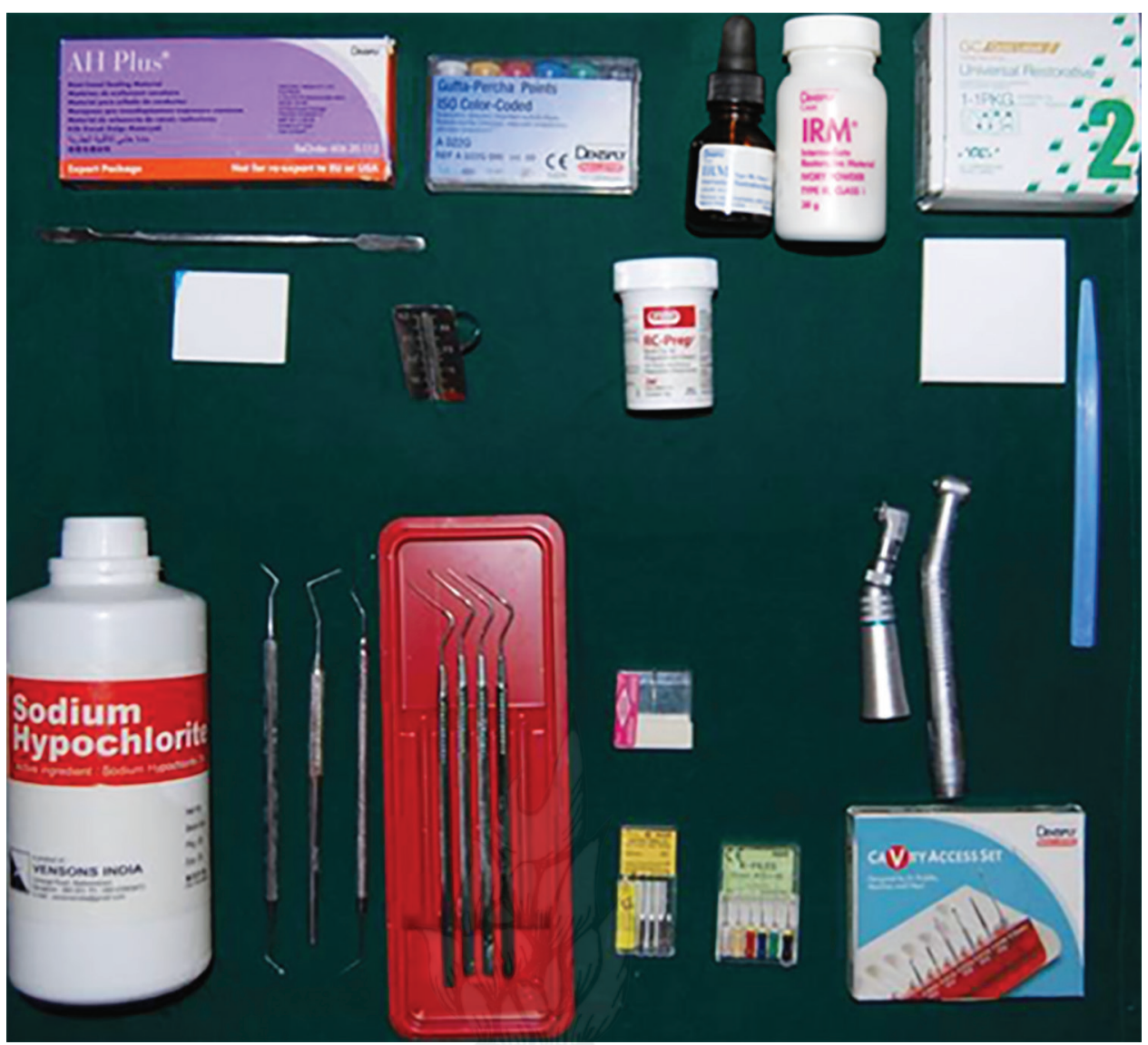

Fig. 2: Root canal preparation armamentarium

Table 1: The material used for bleaching, its concentration and time of application for each group

\begin{tabular}{lll}
\hline Groups & Material & Time interval (days) \\
\hline Group I & Distilled water & 7 \\
Group II & $10 \%$ CP & 7 \\
Group III & $15 \%$ CP & 7 \\
Group IV & $35 \%$ CP & 7 \\
Group V & Sodium perborate mixed & 7 \\
& with 30\% HP & \\
\hline
\end{tabular}

\section{Results}

The mean HP released from various groups listed in Table 2 showed that there is a gradual increase in the mean peroxide release as the concentration of CP increases. In group I, the peroxide leakage was absent. Group II showed mean peroxide leakage to be the least (0.340), followed by group III (0.653), group IV (4.644), and then the highest was for group V (7.536). There was a significant difference found between various groups tested.

In order to find out among which pair of groups there exist a significant difference, multiple comparisons using the Mann-Whitney test was carried out and the results are listed in Table 3. The difference in HP release between groups II and III is found to be statistically significant $(p<0.001)$. Also, the difference in HP release between groups II and IV as well as groups II and V is found to be statistically significant $(p<0.001)$. The difference in HP release between groups III and IV as well as groups III and V was found to be statistically significant $(p<0.001)$. The difference in HP release between groups IV and V was found to be statistically significant $(p<0.001)$.
Graph 1 shows the individual value plot of HP release $(\mu \mathrm{g} / \mathrm{mL})$ in the groups. Group I showed no peroxide penetration. Group II showed the least peroxide penetration which falls in the range of 0.298 to $0.417 \mu \mathrm{g} / \mathrm{mL}$, and group III 0.562 to $0.757 \mu \mathrm{g} / \mathrm{mL}$, and group IV 4.340 to $4.944 \mu \mathrm{g} / \mathrm{mL}$ showed increased peroxide leakage as compared to group II, whereas the highest microleakage is shown by group V $(6.425-7.990 \mu \mathrm{g} / \mathrm{mL})$.

Graph 2 shows the mean HP release $(\mu \mathrm{g} / \mathrm{mL})$ from various groups tested. Group I showed no penetration. Group II showed a mean value of peroxide leakage as $0.340 \mu \mathrm{g} / \mathrm{mL}$. Groups III and IV showed intermediate values for peroxide penetration as 0.653 and $4.644 \mu \mathrm{g} / \mathrm{mL}$, respectively, and group $V$ showed the highest value of $7.536 \mu \mathrm{g} / \mathrm{mL}$.

\section{Discussion}

Discoloration of pulpless and/or endodontically treated teeth is an important concern for both patient and dentist. In recent years, tooth whitening has become one of the most rapidly growing oral care sectors, fueled by patient demands for cosmetically attractive smiles.

Dentin is a permeable structure that allows diffusion of HP. The diffusion through dentin follows Fick's second law. $J_{s}=A \cdot D \cdot C / x$, where $J_{s}$ is the diffusive flux of solute ( $\left.\mathrm{mol} / \mathrm{s}\right), A$ is the surface area available for diffusion $\left(\mathrm{m}^{2}\right), D$ is the diffusion coefficient $\left(\mathrm{m}^{2} / \mathrm{s}\right), C$ is the concentration $\left(\mathrm{mol} / \mathrm{m}^{3}\right)$, and $x$ is the diffusion distance $(\mathrm{m})$. The equation also says that the diffusion stops when the concentration of HP is equivalent on both sides of the dentin. So a bleaching agent needs to be renewed to get satisfactory esthetic results. ${ }^{6}$ 


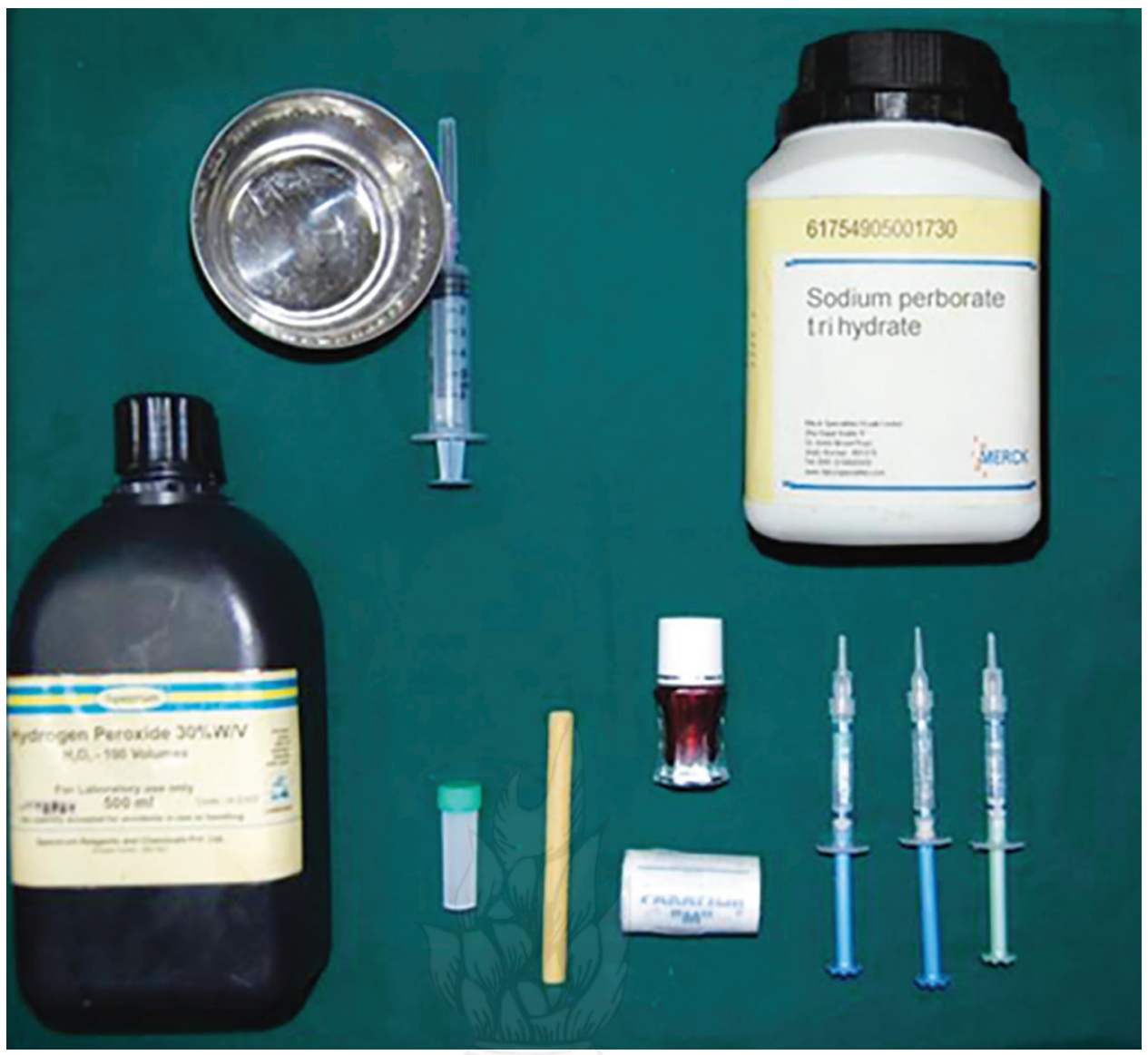

Fig. 3: Bleaching agents used and material for final specimen preparation

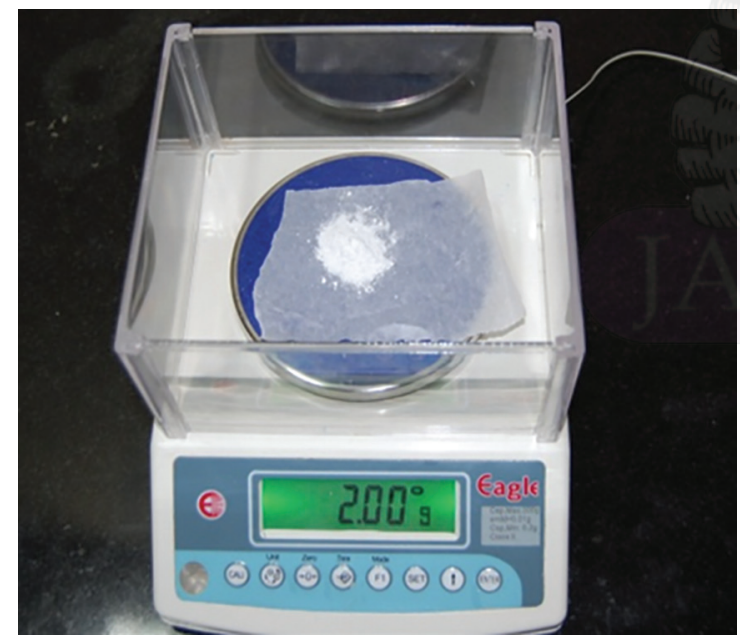

Fig. 4: Weighing apparatus

Studies by Koulaouzidou et al. have demonstrated that intracoronal $\mathrm{HP}$ can diffuse through the root into the periodontal ligament (PDL) space, and this diffusion is greater in the presence of cemental root defects. There is speculation that diffusion of hydrogen ions from intracoronal bleaching agents may provide an acidic environment that is optimal for osteoclastic activity and bone resorption, resulting in external root resorption or invasive cervical resorption. ${ }^{3}$

HP is a ubiquitous molecule produced by a range of oxidase enzymes including glycollate and monoamine oxidases as well as by the peroxisomal pathway for $\beta$-oxidation of fatty acids. Therefore, most

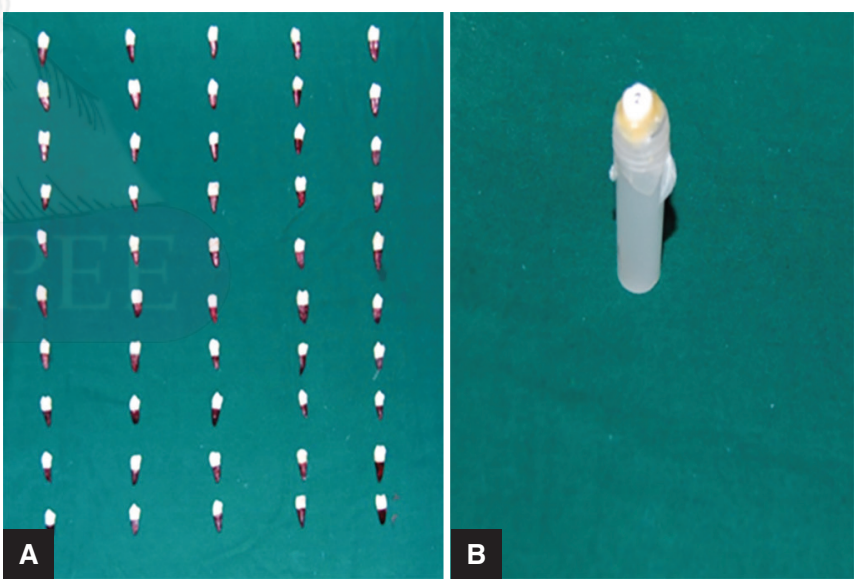

Figs 5A and B: (A) Final specimen prepared and (B) suspending tooth on $5 \mathrm{~mL}$ tube

or all human cells are exposed to some levels of HP, and levels below 20 $\mu \mathrm{mol} / \mathrm{L}$ are considered safe as when it exceeds $50 \mu \mathrm{mol} / \mathrm{L}$, it is cytotoxic to most living cells. A high concentration of $\mathrm{H}_{2} \mathrm{O}_{2}$ is caustic, burns tissues on contact, and can release free radicals. Because of its low molecular weight, this substance can penetrate dentin and can release oxygen that breaks the double bonds of the organic and inorganic compounds inside the dentinal tubules. ${ }^{7}$ Hoffmann and Meneghini demonstrated that HP is toxic to cultured human fibroblasts in concentrations as low as $10 \mu \mathrm{M}(0.34 \mathrm{mg} / \mathrm{L})$, as judged by loss of colony forming ability, which they showed to be due to single strand of DNA. ${ }^{8}$ 


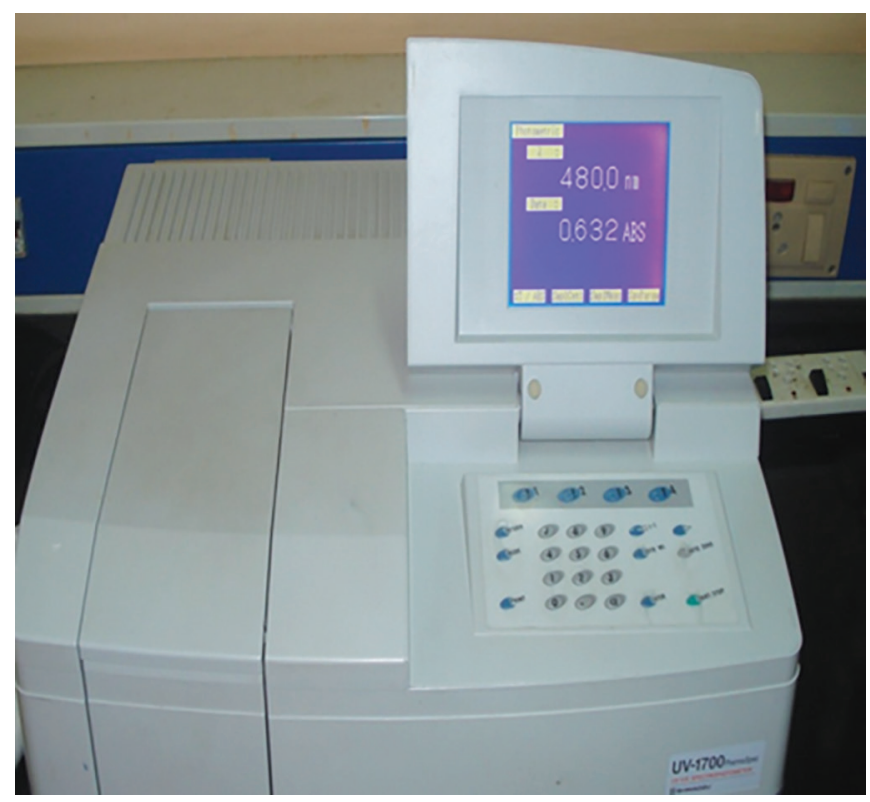

Fig. 6: UV-Visible spectrophotometer

Hence, the estimation of HP penetration from various bleaching agents is essential to know its safety of use. Although bleaching is mainly performed on anterior teeth, premolar teeth were used in this study due to various reasons like they are easily available, and majority of earlier studies on peroxide penetration are done using similar teeth, so a comparison of the results obtained can be done. Young single-rooted premolars were selected which were extracted for orthodontic reasons as this tooth shows a large pulp chamber similar to young anterior tooth, which are the common tooth to get traumatized and discolor, hence, commonly bleached. The premolars were extracted atraumatically using a gauze pad to hold the teeth between the beaks of the forceps, this causes no harm to the CEJ region of the teeth. It is probable that the wide and patent dentinal tubules in young teeth would favor ionic diffusion

Table 2: Comparison of HP release $(\mu \mathrm{g} / \mathrm{mL})$ in all the groups

\begin{tabular}{lllllll}
\hline Group & Mean & Std.dev. & Min & Max & $\begin{array}{l}\text { Kruskal-Wallis } \\
\text { Chi-square }\end{array}$ & $p$ value \\
\hline Group I & 0 & 0 & 0 & 0 & 0 & 0 \\
Group II & 0.340 & 0.033 & 0.298 & 0.417 & 36.589 & $<0.001^{*}$ \\
Group III & 0.653 & 0.065 & 0.562 & 0.757 & & \\
Group IV & 4.644 & 0.208 & 4.340 & 4.944 & & \\
Group V & 7.536 & 0.442 & 6.425 & 7.990 & \\
\hline
\end{tabular}

*Significant difference

Table 3: Multiple comparisons between groups using the MannWhitney test

\begin{tabular}{llll}
\hline Group I & Group (ii) & Mean difference & $p$ value \\
\hline Group II & Group III & -0.313 & $<0.001^{*}$ \\
& Group IV & -4.304 & $<0.001^{*}$ \\
& Group V & -7.196 & $<0.001^{*}$ \\
Group III & Group IV & -3.991 & $<0.001^{*}$ \\
& Group V & -6.883 & $<0.001^{*}$ \\
Group IV & Group V & -2.892 & $<0.001^{*}$ \\
\hline
\end{tabular}

*Significant difference

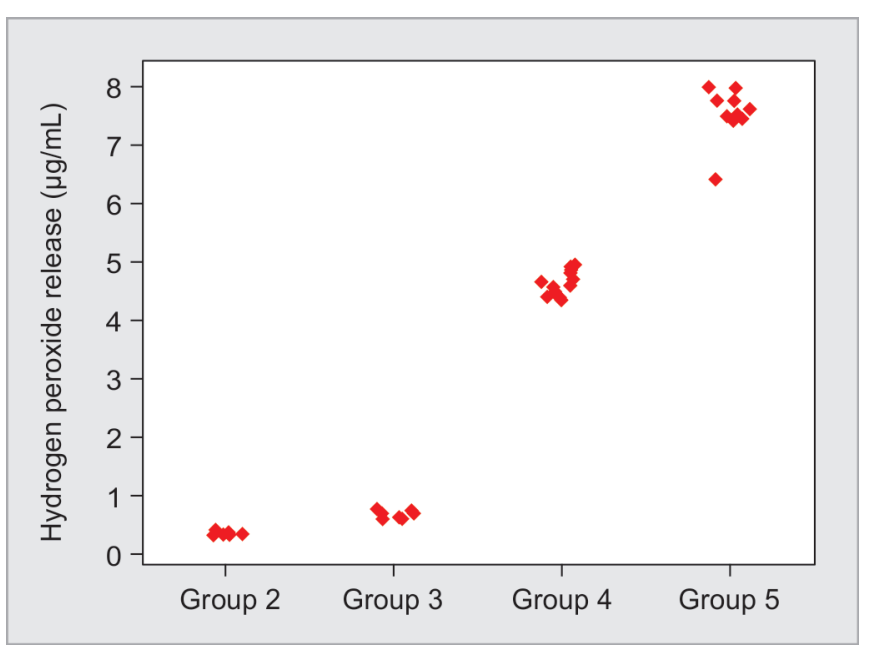

Graph 1: Individual value plot of HP release $(\mu \mathrm{g} / \mathrm{mL})$

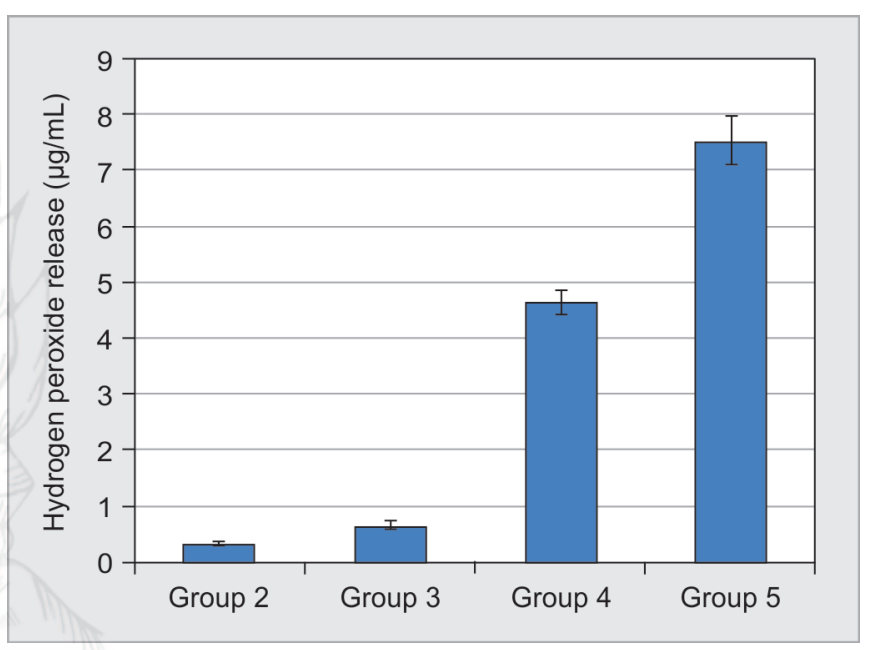

Graph 2: Mean HP release $(\mu \mathrm{g} / \mathrm{mL})$

of the bleaching agent through dentin. Also a study by Schroeder and Sherle found that no dentin exposure was seen at the CEJ of young premolar teeth. ${ }^{9}$

In the current study, conventional glass ionomer cement was chosen as it has the potential to form a chelative bonding to the tooth structure and, therefore, can be successfully used as a protective base before bleaching. Once the bleaching is over, the postendodontic permanent restoration is generally done using the aesthetic material like composite. Use of GIC as a cervical barrier also has the advantage that it can be etched and bonded to the composite. $^{10}$

Studies by Jeremy et al. ${ }^{11}$ have shown that a $2 \mathrm{~mm}$ barrier was sufficient to significantly reduce linear leakage and dentinal penetration into the cervical region. lian Rotstein et al. ${ }^{10}$ in a study found that there is no significant difference found among IRM, zinc oxide eugenol, composite resin, or glass ionomer cement in reducing the radicular peroxide penetration. All the above cement when used in $2 \mathrm{~mm}$ thickness reduces the peroxide penetration.

Among the various forms of the sodium perborate, Weiger and $K u h n^{12}$ found that when a trihydrate form of sodium perborate is mixed with $30 \% \mathrm{HP}$ and used as an intracoronal bleaching agent, it leads to less penetration of peroxide in the cervical region. It was found that there are no differences in radicular peroxide penetration 
between sodium perborate trihydrate mixed with $30 \% \mathrm{HP}$ and sodium perborate tetrahydrate mixed with water.

So in the current study, sodium perborate was mixed with $30 \%$ $\mathrm{H}_{2} \mathrm{O}_{2}$ as it is the most commonly used bleaching agent in clinical practice. This is in accordance with the study done by Gokay et al. ${ }^{13}$ who has also studied peroxide penetration using sodium perborate trihydrate form mixed with $30 \% \mathrm{H}_{2} \mathrm{O}_{2}$. Sodium perborate was mixed with $30 \% \mathrm{H}_{2} \mathrm{O}_{2}$ in the ratio of 2:1 as recommended by various authors. This gives a paste-like consistency which is easy to place in the pulp chamber and sealed using a temporary restoration.

Teixeira et al. ${ }^{14}$ studied the effect of sodium perborate mixed with $\mathrm{H}_{2} \mathrm{O}$ and $30 \% \mathrm{H}_{2} \mathrm{O}_{2}$ and used as intracoronal bleaching agent for the bonding of composite. It was found that sodium perborate with $\mathrm{H}_{2} \mathrm{O}$ or $30 \% \mathrm{H}_{2} \mathrm{O}_{2}$ affects the sealing ability of composite resin restorations performed up to 7 days after bleaching. It was suggested to do the final restoration with composite after 7 days of bleaching.

$\mathrm{CP}$ is a bleaching agent which has been successfully used as night guard bleaching. CP breaks down into urea, ammonia, carbon dioxide, and HP. The amount of HP is one-third of the concentration of the CP used. ${ }^{15}$ Teixeira et al. ${ }^{2}$ used a higher CP concentration of $37 \%$ in a modified walking bleach technique. In four clinical appointments over 1 month, the tooth shade was evaluated. After 4 weeks, a satisfactory tooth color was obtained. Ten months latter a clinical evaluation showed that the lighter tooth shade was maintained and also radiographic assessment revealed no evidence of external cervical root resorption. Sharafeddin and Jamalipour revealed that using 35\% CP bleaching gels had no significant effect on the surface roughness of composite resin. ${ }^{16}$ Lim et al. ${ }^{4}$ in their study found $35 \%$ $\mathrm{CP}$ gel to be equally effective as compared to $35 \% \mathrm{HP}$ gel when used as a intracoronal bleaching agent. They were found to be significantly better than sodium perborate after 7 days. Therefore, 35\% CP gel was recommended as the intracoronal bleaching agent of choice.

This study was conducted in vitro, hence, could not reproduce the clinical variables. Therefore, further in vivo studies with regard to clinical efficiency, long-term stability, and its effect on bonding to composite should be carried out, before it can be recommended for clinical use.

\section{Conclusion}

Within the limitations, the present study concluded that lower concentrations of CP 10 and 15\% produced lower peroxide leakage. Hence, it could be tried as an alternate to traditional agents in cases with compromised tooth which shows cervical tooth defects where the risk of external root resorption is higher.

\section{References}

1. Attin T, Paque F, et al. Review of the current status of tooth whitening with the walking bleach technique. Int Endod J 2003;36:313-329.

2. Cappelletto Nogueira Teihexeira E, Hara AT, et al. Use of $37 \%$ carbamide peroxide in the walking bleach technique: A Case report. Quintessence Int 2003;35:97-102.

3. Koulaouzidou E, Lambrianidis T, et al. Role of cementoenamel junction on the radicular penetration of $30 \%$ hydrogen peroxide during intracoronal bleaching-in vitro. Endod Dent Traumatol 1996;12:146-150

4. Lim MY, Lum SOY, et al. An in vitro comparison of the bleaching efficacy of $35 \%$ carbamide peroxide with established intracoronal agents. Int Endod J 2004;37:483-488. DOI: 10.1111/j.1365-2591.2004.00829.x.

5. Leonard RH, Sharma A, et al. Use of different concentrations of carbamide peroxide for bleaching teeth. An in vitro study. Quintessence Int 1998;29(8):503-507.

6. Camps J, de franceschi $\mathrm{H}$, et al. Time-course diffusion of hydrogen peroxide through human dentin: clinical significance for young tooth internal bleaching. J Endod 2007;33(4):455-459. DOI: 10.1016/j. joen.2006.12.006.

7. Plotino G, Buono L, et al. Non vital tooth bleaching: a review of the literature and clinical procedures. J Endod 2008;34(4):394-407. DOI: 10.1016/j.joen.2007.12.020.

8. Hoffmann ME, Meneghini R. Action of hydrogen peroxide on human fibroblast in culture. Photochem Photobiol 1979;30(1): 151-155.

9. Schroeder E, Scherle WF. Cemento-enamel junction-revisited. J Periodontol Res 1988;23(1):53-59.

10. Rotstein I, Zyskind D, et al. Effect of different protective base materials on hydrogen peroxide leakage during intracoronal bleaching in vitro. J Endod 1992;18(3):114-117. DOI: 10.1016/S0099-2399(06)81310-5.

11. Smith JJ, Cunningham CJ, et al. Cervical canal leakage after internal bleaching procedure. J Endod 1992;18(10):476-481.

12. Weiger R, Kuhn A, et al. Radicular penetration of hydrogen peroxide during intracoronal bleaching with various forms of sodium perborate. Int Endod J 1994;27:313-317.

13. Gokay O, Ziraman F, et al. Radicular peroxide penetration from carbamide peroxide gels during intracoronal bleaching. Int Endod J 2008;41:556-560. DOI: 10.1111/j.1365-2591.2008.01384.x.

14. Teixeira ECN, Hara AT, et al. Effect of non-vital tooth bleaching on microleakage of coronal access restorations. J Oral Rehabil 2003;30:1123-1127.

15. Demarco FF, Freitas JM, et al. Microleakage in endodontically treated teeth: influence of calcium hydroxide dressing following bleaching. Int Endod J 2001;34:495-500.

16. Sharafeddin F, Jamalipour GR. Effect of $35 \%$ carbamide peroxide gel on surface roughness and hardness of composite resins. J Dent 2010;7(1):6-12. 